\title{
برنامج الكورت لتعليم التفكير فى ضوء المعايير القومية لرياض الأطفال في مصر
}

$$
\text { إعــداد }
$$

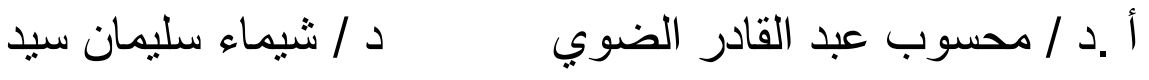

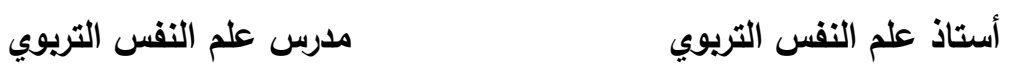

$$
\begin{aligned}
& \text { بكلية التربية بقتا- جامعة جنوب الواداي بكلية التربية بقتا - جامعة جنوب الواداي }
\end{aligned}
$$

$$
\begin{aligned}
& \text { أ/ لمياء عبد الرسول عبد الرحيم احمد } \\
& \text { باحثة ماجستير بقسم علم النفس التريوي } \\
& \text { كلية التربية بقتا - جامعة جنوب الوادي }
\end{aligned}
$$




\section{المستخلص : n (الم}

يعرض المقال ( برنامج الكورت لتعليم التفكير ونواتج تعلم الرياضيات والعلوم تبعا" للمعايير القومية لرياض الأطفال في مصر) ، حيث يتضمن برنامج الكورت لتعليم التقكير ليشمل الاجزاء التالية (اولا توسعة مجال الادراك ، ثانيا التتظيم ، ثالثا التقاعل ، رابعا الابداع ، خامسا المعلومات والعواطف ، سادسا الفعل كتاب " للمعلم ، للطالب " ) ، ان نواتج تعلم الرياضيات فتشمل علي مجالات ومعايير وهي ( مجال الاعداد والعلاقات العددية ، مجال التقدير والحساب العقلي ، مجال القياس ، مجال الهندسة والحس المكاني ، مجال العلاقات الجبرية والبيانات ) ، ان نواتج تعلم العلوم فتتمل علي مجالات ومعايير وهي ( مجال المعرفة الفيزيقية ، مجال علوم الحياة ، مجال البيئة وعلوم الارض ، مجال التطبيقات التكنولوجية ) ، حيث استخدمت الباحثة ثلاثة اجزاء من برنامج الكورت وهما ( توسعة مجال الادراك ، التنظيم ، الابداع ) في ضوء

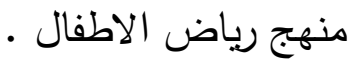
الكلمات المفتاحية :- برنامج الكورت لتعليم التفكير - المعايير القومية لرياض الاطفال 


\title{
The Cort programme for learning Thinking in According to the National Standards of Kindergarten in Egypt
}

\section{A.DR/ Mahsoub Abd Qader Al-Dawi \\ D.R/ Shaimaa Sulaiman Sayed \\ Lamiaa Abd Rasoul Abd Rahim Ahmed}

\begin{abstract}
:
This Article presents the Cort Programme for learning Thinking, and the Outcomes of learning Maths and Science, According to the National Standards of Kindergarten in Egypt, the Cort Programme for learning Thinking to include the following parts ( First Breadth , Second Organization, Thirdly Interaction , Fourthly Creativity, Fivthly Information \& Feeling, Sixthly Action " the Teacher and the Student " ) . the learning of Outcomes of Mathematics include fields and Standards (field of Numbers and Numerical relations, field of Assessment and Mental Calculation , field of Measurement , field of Engineering and Spatial Sense and field of Algebraic Relations and Data ) . the learning of Outcomes of Science include fields and Standards ( field of Physical Knowledge, field of Life Science, field of Environment and Earth Sciences and field of Technological Applications ), the Researcher used Three Parts of the Cort Programme ( Breadth, Organization and Creativity ) in According of the Curriculum of Kindergartens .
\end{abstract}

\section{Key Words :-}

The Cort Programme for Learning Thinking - The National Standards of Kindergarten . 
نظرا لتطور الاتجاهات المعاصرة أصبح هناك أهتمام متزايد بتوجيه الجهود لتحسين عمليات التعليم والتعلم ، فلم يعد هدف العملية التربوية يقتصر علي اكتساب الطفل المعارف والحقائق بل تطورالهدف إلي تتمية قدرته علي التفكير والتحليل والنقد والتعميم والابتكار ، صاحب ذلك أيضا نزعه قوية نحو الاهتمام بتتمية الشخصية المتكاملة لطفل ، أصبح الاهتمام بالتقكير ضرورة ملحة في هذا العصر الذي يتميز بالتغيير السريع في مختلف جوانب الحياة، وأصبح تتمية التفكير عند الطلبة هدفا رئيسيا من أهداف التربية المعاصرة، من أجل إعداد جيل قادر على مواكبة هذا التغير، واستيعاب الكم الهائل من تطور المعرفة. وبالتالي تتميتها واستثمارها بصورة تحقق لهم فهم أفضل لأحداث للحياة.

يعد التفكير عملية عقلية يتم عن طريقها معرفة الكثير من الأمور، فهو نشاط عقلي راقي وقدره من القدرات العقلية العليا التي تميز الإنسان عن غيره من الكائنات الحية الاخري ويعد التفكير من المحددات الأساسية للسلوك ومن المؤثرات المهمة في صياغة السلوك، ادي ذلك إلي أختلاف أنماط التفكيرلتعدد تعريفاته واتجاهاته حسب ما وفره التراث النفسي والتربوي ولذلك فأن الحاجة تبدو ملحة إلي تعليم التفكير وإكساب التتلاميذ المهارات بطرق مختلفة ولن يتم ذلك إلا بإدخال برامج التعليم المباشر لمهارات التفكير ضمن المنهج المدرسي ، ويري التربويون انه من الواجب علي المعلم أن بزيد من النشاط التفكيري عند الطلاب ويعتبر ذلك من أساسيات وظيفة المعلم وبالفعل يجب علي المعلم تدريس كيفية التفكير للأطفال . 
سوف نتناول تعريف برنامج الكورت وأهدافه واستراتيجياته وأهميته وأدواته والمستقيدين منه ووحداته لتطوير التعليم والارتقاء بجودته لإصلاح العملية التعليمية في مصر ، لتوضيح فعالية واثز استخدام برنامج الكورت في ضوء المعايير القومية لرياض الأطفال في مصر

تعد مرحلة الطفولة من المراحل المهمة في نمو الطفل وتربيته ففيها نتكون باكورة الطفل الأولي مع البيئة ولذلك أكد علماء النفس أن هذه المرحلة يتكون خلالها الكثير من مفاهيم الطفل وأنماط سلوكه ، والاهتمام بالأطفال هو في الواقع اهنمام

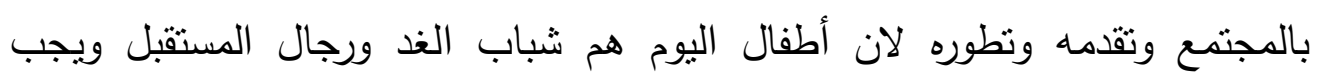
إعدادهم الأعداد السليم للحياة ـ أن التفكير عملية يومية مصاحبة للإنسان بشكل دائم كالمشي فهو أداء طبيعي يومي نقوم به باستمرار ، نظرا لأهمية التفكير وحاجة الأفراد له والتغيرات التي طرأت بفعل التكنولوجيا والتطلعات الاجتماعية وفي هذا المجتمع المعقد ظهرت الحاجة للتقكير بطرائق جديدة .

\section{- التعريف ببرنامج الكورت :The Cort:-}

يعد برنامج كورت لتعليم التفكير من اشهر البرامج العالمية وأكثرها تطبيقا. وضعه عالم التفكير الثهير دي بونو (De Bono)، واشتق أسم البرنامج من أسم لئمن Cognitive Research "المؤسسة التي قامت بنشره وتطويره مؤسسة البحث المعرفي

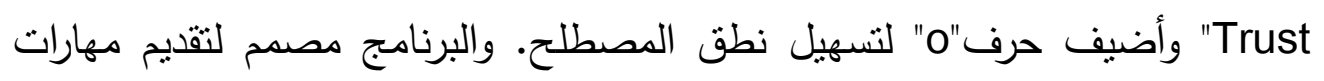
التفكير من خلال مجموعة من الأدوات العملية التي يدرب الطلاب على استخدامها في مواقف منتوعة، مع ضرورة نوافر فرص تدريبية كثيرة ومنتوعة يطبقون الطلاب من بن

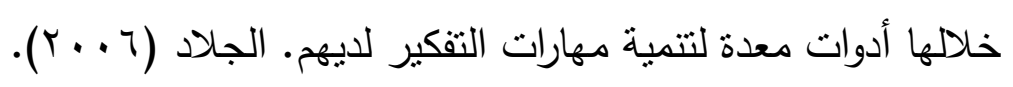


يعد إدوار دي بونو هو السلطة الرائدة في التفكير والابتكار التتظيمي ، والقيادة الإستراتيجية والإبداع الفردي وحل المشكلات وجلبت له الأدوات والأساليب الأحصائية

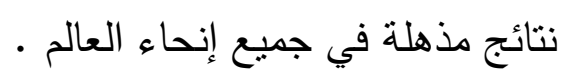

وكان له الفضل في إنتاج أساليب التفكير ومنها التفكير الست Hats ، برنامج الكورت Cort ، التفكير الجانبي ،الاهتمام المباشر بأدوات التفكير •

ويجري حاليا تتفيذ الدورات التدربية في المؤسسات وسعيهم إلي تغير السلوك والتفكير ، تعزيزالأبتكار وزيادة الإنتاجية

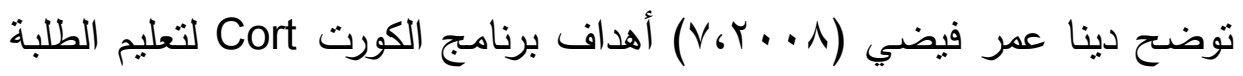

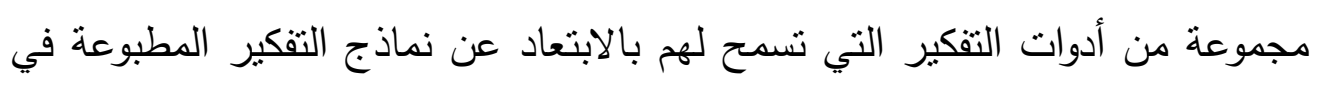
الذهن ، ومحاولة إدراك الأشياء بشكل أكثر وضوحا وتحررا وفي تطوير اتجاهات أكثر إبداعا لحل المشكلات فيصبح الطلبة من خلال دراسة هذا البرنامج مفكرين مبدعين . يوسع برنامج الكورت Cort الإدراك وذلك عن طريق استخدامه في تقديم مهارات التفكير المصممة بدقة للطلبة كأدوات عملية يمكن استخدامها ،من ثم يتدرب الطلبة

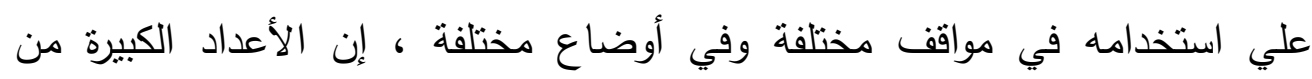
المواضيع التي ينم التدرب عليها وتتوعها وسرعة إجراء المهام ، إذ يجب أن تبقي الأداة

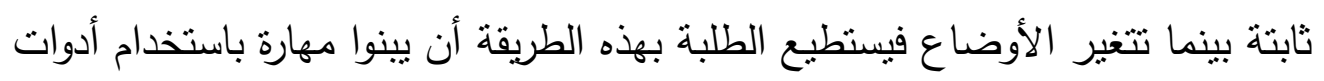

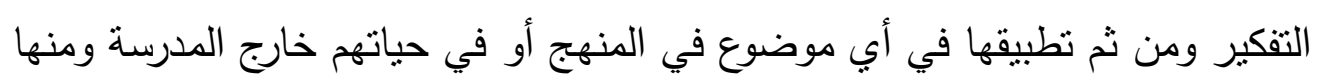


يتمتع برنامج الكورت لتعليم التفكير بمميزات متعددة ومن خصائص برنامج

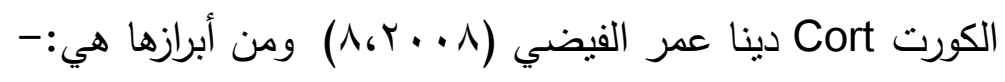

برنامج بسيط وعملي ويمكن للمعلمين استخدامه كل حسب طريقته .

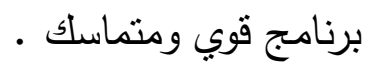

برنامج لله تصميم منوازن إذ إن كل مستوي تدريبي مستقل تماما عن الأخر • برنامج يهيئ الطلبة ليصبحوا مفكرين مبدعين برنامج يستمتع الطلبة في تدريسه .

تسمح مرونة برنامج Cort لتعليم التفكير بدمجه في المنهج بأي طريقة براها المعلم

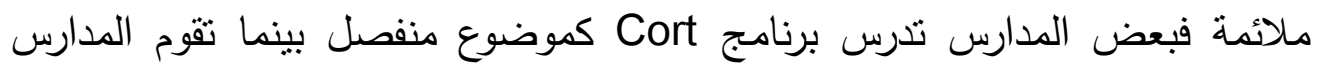
الأخرى بدمجه في موضوع معين أو في المنهج • لغندين

يمكن استخدام مواد Cort لجميع الطلبة وفي جميع الفئات العمرية من المدارس الأبتدائية حتي المرحلة الجامعية ولكن السن المناسبة أكثر هي سن التاسعة عشر ويمكن أستخدامها مع طلبة أصغر سنا .

يجب علي الطلبة إنجاز درس Cort واحد في حصة لا تتعدي مب دقيقة ومن ثم فإن دروس البرنامج الستين يمكن أن تمتد لسنتين أو ثناث سنوات وبعد أن يتعلم الطلبة

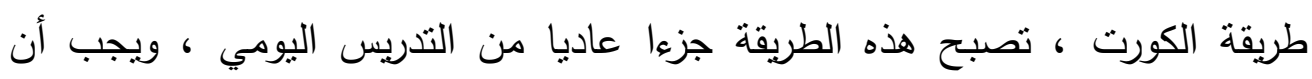
Cort تشتمل كل حصة علي فقرتين تدربييتين حتي يسنطيع الطلبة فهم وتطبيق أدوات 


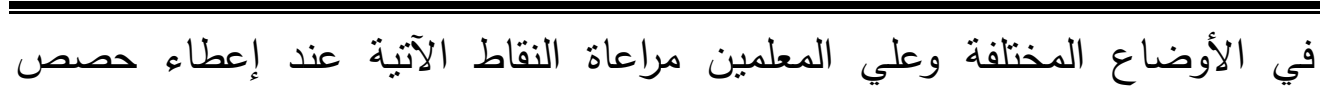

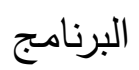
إعطاء فقرتين في كل جلسة علي الاقل . المحافظة علي النظام داخل الحصة . التركيز علي مهارة التفكير أكثر من مضدون الفقرة التذريبية . أعطاء الطلبة الاحساس بالانجاز

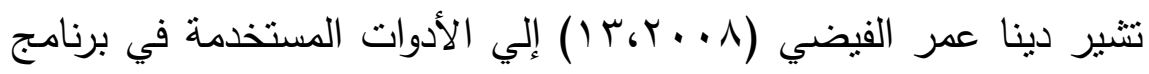
الكورت لتعليم التفكير هو الإدراك وذلك باستخدام طريقة الأداة كمنهج في تعليم التفكير

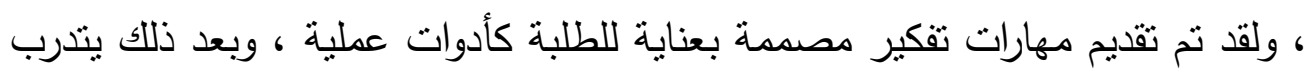
الطلبة علي استخدام الأدوات في تقديم مواقف متتوعة ـ أن الكم الكبير من الفقرات

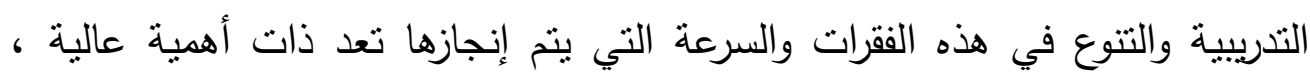

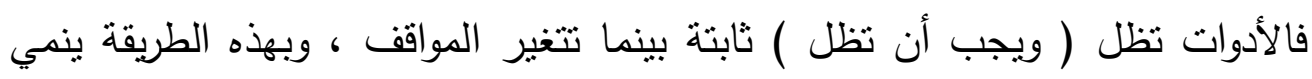
الطلبة مهاراته في استخدام أدوات التفكير كيعد ذلك باستطاعتهم نقلها في أب من نابنه نواحي المنهج أو في حياتهم العامة خارج المدرسة .

فالعملية المباشرة لبرنامج الكورت هي :أداة تلدريب تغيير وفوق كل ذلك صممت مهارات الكورت لتكون عملية . ووضحت دينا عمر فيضي (1 . . 10، 1) أنه يمكن دمج برنامج الكورت لتعليم التقكير مع المنهج ، حيث أن مرونة برنامج الكورت جعلته قابلا للاخول في المنهج 
المدرسي بأي طريقة تناسب المعلم علي الوجه الأحسن فبعض المدارس تدرس الكورت

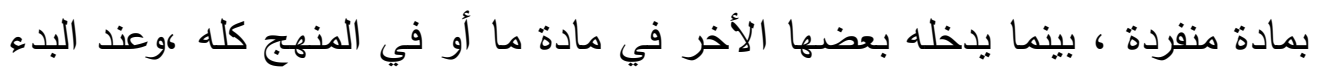

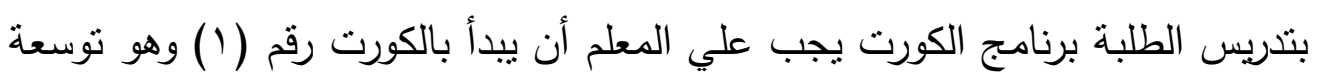

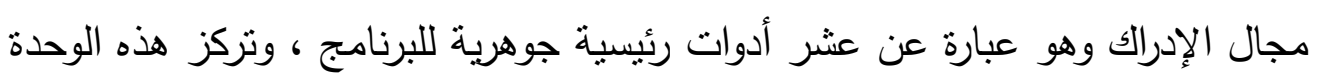
علي توسيع الإدراك كمهارة أساسية في برنامج الكورت وبعد ذلك يمكن استخدام بقية الإدرات

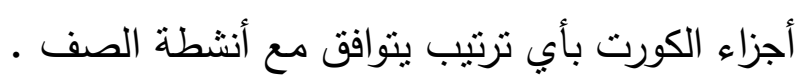

يتبع البرنامج تصميما متوازنا بدل الترتيب الهرمي إذ أن المعلم يمكنه أن يختار أي جزء من أجزاء الكورت لتعليمه للطلبة وذلك بعد الانتهاء من الجزء الأول من البرنامج والذي يعد الجزء الأساسي من البرنامج مما يضدن القيمة المستقلة لكل درس حتي في

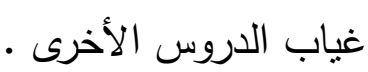

من هنا يمكن توضيح المستقيدين من برنامج الكورت لتعليم التفكير حيث صمم إدوارد دي بونو (1 . . Y، T 1 ) دروس الكورت لتنكون خلالها أفكار الطالب بحيث لاتكون متفقه بالضرورة مع مستوي ذكائه بل صممت دروس الكورت لتنشيط هذه المهارة لتعليم الطلبة ذوي القدرات المختلفة لتطبيق ذكائهم بشكل فعال علي المواقف الأكاديمية أو الثخصية أو الاجتماعية .

كما يمكن استخدام مواد الكورت للطلبة في جميع الأعمار من ( المرحلة الابتدائية حتي الجامعة ) حيث نزكز جميع وحدات الكورت علي الـ Operacy وهي مهارة تفعيل

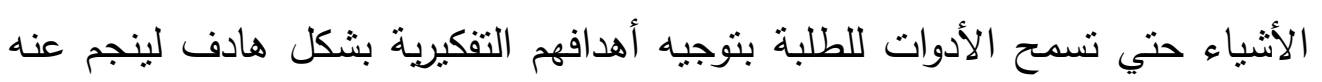

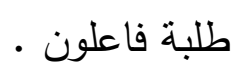

- ولقد صمم دي بونو برنامج الكورت ليتوافق مع المعايير وهي :- 
إن البرنامج بسيط وعملي ويمكن إن يستخدمه المعلمون في تمثيل مجموعة واسعة من

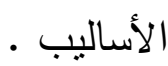
إن هذا البرنامج متماسك بحيث ييقي سليما علي مدار انتقاله من متدرب إلي متدرب أخر ومن معلم إلي طالب .

إن هذا البرنامج لديه تصميم منوازن يعني أن كل جزء فيه يمكن استخدامه والأستفاده

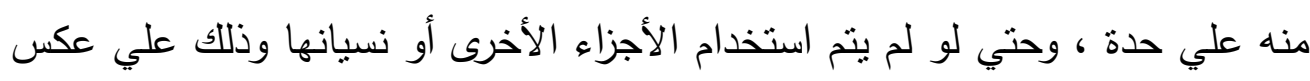
البرامج الاخري وذللك التصميم الهرمي الذي بتنطلب فيها تعليم الهيكل أو البناء بأكمله

هذا البرنامج يمكن الطلبة من ان يكونوا مفكرين فاعلين ومتفاعلين في الوقت نفسه ،

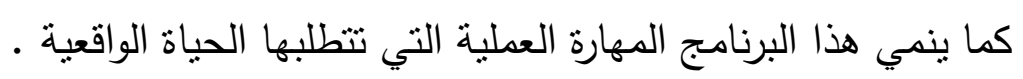
• يستمتع الطلبة بدروس التفكير - الاستراتيجيات المقترحة في استخدام الكورت إدوارد (^ . . Y، ج):الإستراتيجية الأولي :- مهارات التدريب الأساسية

يتم هنا باستخدام (Cort 1 ) وهو الحد الأدنى من مهارات التقكير الأساسية التي يجب تعليمها لجميع الطلبة بغض النظر عن العمر أو القدرة . لمهن الإستراتيجية الثانية :- التفكير الإبداعي ويتم هنا استخدام (Cort 1 ) ومن ثم (Cort 4) ويتم استخدام هذه الإستراتيجية مع الأشخاص الذين لديهم اهتمام خاص بالتفكير الإبداعي والكتابة الإبداعية . 
يتم هنا استخدام (Cort 1 ) ومن ثم ( Cort 4 ) وثث ( Cort 5 )

الإستراتيجية الرابعة :- التفكير المتفاعل والناقد :-

يتم هنا استخدام ( Cort 1 ) Cort 3 ، Cort

الإستراتيجية الخامسة :- المادة المتكاملة :-

تعطي هنا جميع مواد Cort الست .

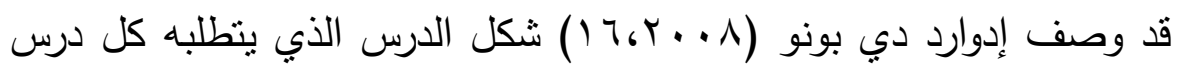
قرابة هب دقيقة ومع ذلك يستطيع المعلم تحديد إن كان الصف أو أسلوب التعليم يتطلب وقتا أكثر ، فعلي سبيل المثال يمضي بعض المعلمين قرابة ساعة في شرح الدرس الواحد ، أو يقومون بتدريس درس واحد خلال فترتين متباعدتين وكل فقرة تستغرق هب دقيقة .

- يجب أن تتضمن كل جلسة فقرتي تدريب علي الاقل ليفهم الطلبة إمكانية تغيير أداة التقكير في مواقف مختلفة في هب دقيقة لا تستوعب أكثر من فقرتين وفي الفقرات الأطول قد نسمح الفرصة لمزيد من التدريب والتغذية الراجعة ، ويوضح المعلمون بالتوازن بين شكل الدرس والصفوف والأساليب المستخدمة في التدريس ويقوم بعض المعلمين بتطوير فقرات تدريب مألوفة وبعضهح يستخدم وسائل إيضاح وأجهزة الفيديو ووسائل تساعد علي تسهيل وممارسة أدوات التفكير وتوضيحها ، ففي تتويع شكل الدرس وعلي المتعلمين أن يتذكروا الأتي:- 
أن يتضمن الدرس ما لايقل عن فقرتين تدريبيتين .

المحافظة علي الضبط وتتشيط المحيط .

تركيز الدرس علي عملية التقكير بدلا من مضمون المناقثة .

جعل الطلبة يحسون أنهم قادرون علي الإنجاز •

- الأساس العلمي الأي يقوم عليه البرنامج :-

ينطلق دي بونو (919 (19) في برنامجه للتفكير من مسلمة قوامها انه يمكن تعليم

التفكير ، علي اعتبار أن التفكير يبسط الأشياء والمواقف ولا يعمل علي تعقيدها ويجب أن ننظر إليه كعملية بسيطة وأن ذلك لن يتم الا من خلال تعليم التفكير

يركز برنامج الكورت علي مفهوم خاص للتفكير والإدراك والعلاقة بينهما، فعندما نتعامل مع التقكير فإننا نتعامل مع الإدراك الواعي وحينما نتعامل مع الإدراك الواعي فأننا نتعامل مع أنماط التفكير ، وعندما نتعلم مع أنماط التفكير علينا استخدام موجهاته أي أدواته ، إن النظر في اتجاه معين لا يولد أفكارا ولا يعالج معلومات وانه ببساطه ليضع أمام تفكير الفرد جزءا من خبرته ل

- محاور برنامج الكورت لتعليم التفكير :- 


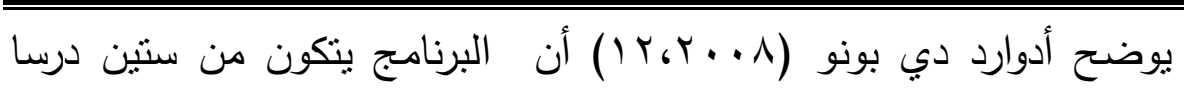
موزعه علي ستة أجزاء يحتوي كل جزي منها علي عشرة دروس ،كل جزء يحمل أسما بتضمن هدفا يفترض تحقيقه

عند الانتهاء من هذا الجزء فضلا عن أن كل جزء من الأجزاء الستة يتناول جانبا واحد من جوانب التفكير

إلي أن برنامج الكورت يهدف إلي تعليم مهارات التنريب الأساسية ، والتفكير الإبداعي ، والتفكير العام ، والتفكير الناقد المتفاعل حيث يهتم كل درس من دروسه بتتمية ناحية تفكيرية معينه ولكل جزء كتاب خاص بالمعلم يوضح ويشرح كل درس ويمكن عرض

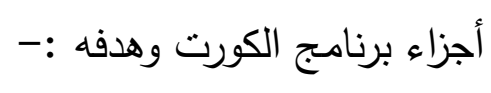

- أجزاء برنامج الكورت لتعليم التفكير (Cort) -

\begin{tabular}{|c|c|c|}
\hline 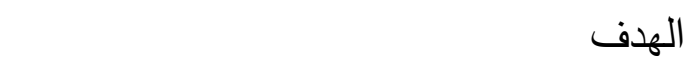 & 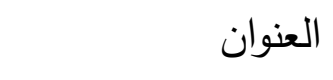 & 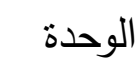 \\
\hline النظر إلي الموقف من جميع جوانبه & توسعة مجال الإدراك & الأول \\
\hline يهتم بالانتباه والتزكيز علي المواقق بفعالية & 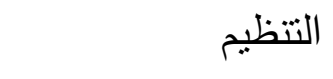 & 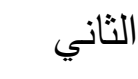 \\
\hline التفكير الناقد مناقثة الأدلة والدجج المنطقية وتتمية & التفاعل & الثالث \\
\hline يعرض استراتيجيات توليد الأفكار ومعالجنها & 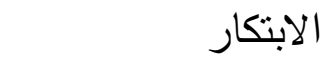 & 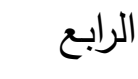 \\
\hline يهتم بالعوامل الانفعالية المؤثرة في التفكير & المعلومات والعواطف & 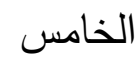 \\
\hline تشتكيل الخطة لاتجاز العطل والوصل لحل & الفعل & السادس \\
\hline
\end{tabular}




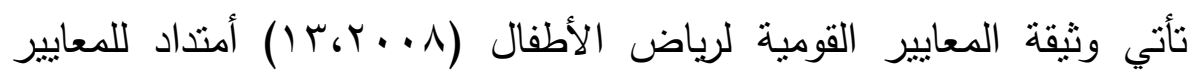
القومية للتعليم في مصر التي صدرت وثثتتها في عام (ץ+.. r) وتتأتي أهمية بناء معايير قوميه لرياض الأطفال :

* التطلع إلي مد مظلة ضمان الجودة واعتماد لتشمل مؤسسات رياض الأطفال بمدخلاتها وعملياتها ومخرجاتها

* أن لمرحلة رياض الأطفال خصوصيتها التي تميزها عن مراحل التعليم قبل الجامعي من حيث الأهداف وطبية المتعلمين ومحتوي البرنامج التعليمي وأساليب التعليم والتعلم * الإفادة من الخبرات المنراكمة عن التعامل مع المعايير القومية للتعليم علي مسنوي الفكر والتطبيق معا * مراعاة المتغيرات والمستجدات علي الساحة التربوية

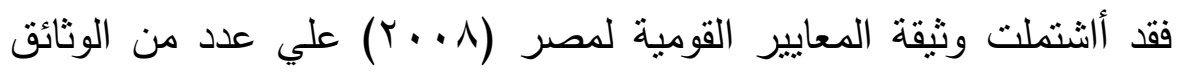
الفرعية بلغ مجموعها ست وثائق ، وكل وثثقة منها تتعامل مع مكون من مكونات التربية في مرحلة رياض الأطفال ، وكل وثثقة تتفرع إلي مجالات ، ثم إلي معايير ومؤشرات ـ حيث تتصدر ( نواتج التعلم ) وثيقة المعايير باعتبارها توصيف للغايات أو المخرجات المستهدفة بحيث يمكن الاسترشاد بها في فهم معايير المحتوي والمعلمة والروضة الفعالة ، وقد نوع من مجالات نواتج التعلم لكي تغطي مختلف جوانب النمو 
في شخصية الطفل الجسمي والحركي والانفعالي الاجتماعي ، وأساليب التعلم واللغة والتواصل ، والوعي والمعرفة ، وهو ما يتفق مع التصنيف العالمي لنواتج التعلم في

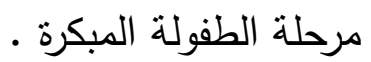

ومن الامور المهمة التي تعين علي تتبع التطور التعليمي لدي اطفالنا ان نحدد مسبقا تلك المواصفات والخصائص التي نتوقع ان يكتمل تكونها لدي الطفل مع انتهائه من مرحلة رياض الاطفال ،ومكونات هذه المواصفه هي ما نسميه بنواتج التعلم ، وتتضمن مستويات معيارية لكل ما يجب ان يحمله المتعلم ويكتسبه عبر مرحلة رياض الاطفال من معارف ومهارات شخصية واجتماعية التي تمكنه من التنشئة السليمة وإعداد شخصيته وتتمية قدراته بما يمكنه من التطور التربوي وتتكون وثثقة معايير المحتوي لنواتج تعلم الرياضيات والعلوم من الاتي : - مجالات ومعايير ومؤشرات الرياضيات وهي :مجال الاعداد والعلاقات العددية

المعيار :- فهم الخواص الاساسية للمفاهيم العددية وتوظيفها .

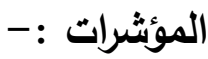

يعد وحدات حتي العدد · ا ويتابع حتي العدد · ب ، يثبت فهمه لـفاهيم واحد فاكثر ، يتعرف علي موضع العناصر في منتابعه عددية ، يقارن المجموعات ويرتبها ـ مجال التقدير والحساب العقلي 
المعيار :- استخدام الطرق الاساسية عند اجراء العمليات الحسابية .

يوظف الاعداد في حل المشكلات ، يستخدم الاشياء والرسومات لنمذجة والحل ، توظيف اساليب التفكير وحل المشكلات في العمليات الحسابية ، يتوصل إلي بدائل في

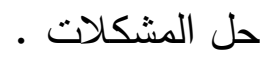

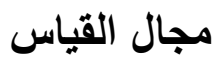

المعيار : - فهم الخواص الاساسية لمفاهيم القياس وتوظيفها .

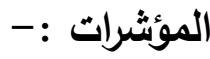

يثبت فهمه لمعاني والمصطلحات ، يحدد الوقت بالساعات ويرتب الاحداث ، يقارن خواص الاجسام ، يقيس الاطوال بادوات غير مقننة ، يميز العملة المصرية بفئاتها . مجال الهندسة والحس المكاني المعيار :- فهم الخواص الاساسية للمفاهيم الهندسية وتوظيفها .

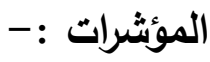

يتعرف علي اسماء بعض الاشكال الهندسية ، يعرف العلاقات المكانية ، يميز بين الاشكال المتشابهة والمختلفة مجال العلاقات الجبرية والبيانات 
المعيار:- فهم الخواص الاساسية لمفاهيم العلاقات الجبرية ومعالجة البيانات وتوظيفها - ونيا.

يجمع الاثشياء وفقا لخصائصها ، يرسم البيانات باستخدام الصور والاعداد والاثكال ، يكرر نمطا ذا خاصية بسيطة ، يثبت فهمه لمصظلاحات .

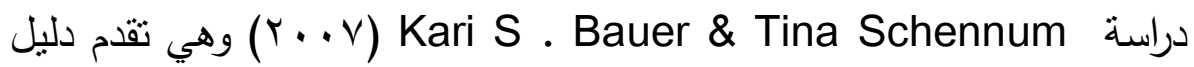
لتدريس الرياضيات ماقبل الروضة ومعايير المحتوي ، الاطفال الصغار يتعلمون الرياضيات الطبيعية وانها تبدو طبيعية لانماط والاثكال ، وجعل المقترنات ردبات واستكثاف العلاقات داخل بيئتهم في مرحلة الطفولة المبكرة لما يمتلكون من الفضول طبيعي وحاجه لفهم العالم ويستتد كل هذا علي ان الاطفال يحتاجون انشطة هادفة التي تساعدهم علي تطوير واستخدام المفاهيم الرياضية واللغه والعمليات

الحسابية ويجب تمكين الاطفال لتوسيع فهمه لعدد والثكل والحجم والنمط وهناك قائمه ببعض التعاريف المرتبطة بالرياضيات وهي :-

السمة وخاصية (مثل الحجم ، واللون ، والثكل ، والوزن ) تصنيف النوع والثكل في مجموعات حسب خصائصها وقارن ووصف العلاقة بين اثنين واكثر * والتقدير لكمية والحجم تمدد والهندسة المكانية

مجالات ومعايير ومؤثرات العلوم وهي :- 


\section{مجال المعرفة الفيزيقية}

المعيار :- تتمية معرفة الطفل بالفيزياء الكونية

\section{- المؤثرات : - -}

يلاحظ اثر القوة في في تغيير حالة الجسم ، يميز العوامل المؤثره في تحريك الاشياء ، يميز قوانين القوة ، يعرف ان لماء والهواء اثر في تحريك الاشياء ، يميز بين الاجسام المنفذة وغير منفذة للضوء ، يدرك الاختلاف بين حجم الظل وحجم صاحب الظل ، يتعرف علي ظاهرة البرق ، يتعرف علي ناثير القوة المغناطيسية ، علي التطبيقات ومظاهر القوة الكهربائية ، يتعرف علي طبيعة المادة .

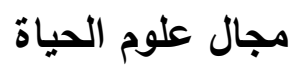

المعيار :- تتمية معرفة الطفل بالكائنات الحية وتعامله معها

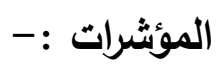

يصنف الكائنات الحية وغير الحية ، يتعرف علي مظاهر التغير في الحياة ، يتعرف علي وظائف الاعضاء في الكائنات الحية ، يربط بين احتياجات الكائن الحي وبيئته وخصائصها ، يلاحظ اهية الكائن الحي للانسان ، يرعي الكائن الحي ويحافظ عليه.

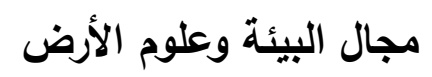
المعيار :- - تتمية معرفة الطفل بالبيئة وعلوم الارض

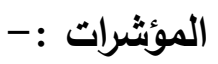


يعرف انواع البيئات وخصائصها ، يصنف العناصر الطبيعية في البيئة المحيطة به ، يتعرف علي العناصر الملوثة للبيئة يتعرف علي اهمية الهواء . مجال التطبيقات التكنولوجية المعيار : - تتمية معرفة الطفل بتطبيقات التصميم التكنولوجي

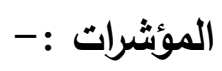

يتعرف علي نموذج الالة ، يصف كيفية تشغيل الالة ، ويحدد وظيفة الالة وما تقدمه للانسان ، يتعرف علي الطرق الامنة للتعامل مع الالات . - تشير المعايير القومية لرياض الأطفال إلي انه لابد من متابعة التطور التعليمي لدي أطفالنا التي تمكنه من التنشئة السليمة وأعداد شخصيته وتتمية قدراته عبر المراحل التعليمية .

وتهدف وثيفة المعايير إلي تحديد خصائص ومواصفات المتعلم الذي انهي دراسته في مرحلة رياض اطفال في المجالات المختلفة لنواتج التعلم وما نتوقعه من الطفل بنهاية

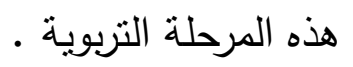


إبراهيم احمد الحارتي (9 . . r) ـ تعليم التفكير ، طء ، القاهرة ، الروابط العلمية للنشر

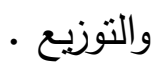

إدوارد دي بونو (^ . . ب) برنامج الكورت لتعليم التفكير دليل البرنامج ،( ترجمة دينا عمر فيضي) ، الأردن ، دار الفكر.

سناء محمد سليمان (1) (1) . التفكير وأساسياته وأنواعه التعليمية وتتمية مهاراته ،

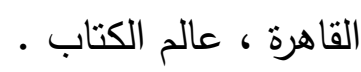

عصام علي الطيب († + . ץ) ـ اساليب التقكير نظريات ودراسات وبحوث معاصرة ،

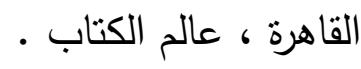




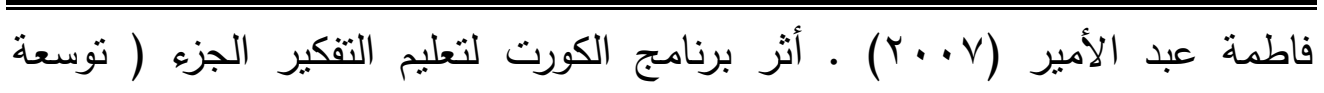
الإدراك ) في تحصيل تلامذة الصف الخامس الايتدائي وتقكيرهم الالبداعي ، مجلة

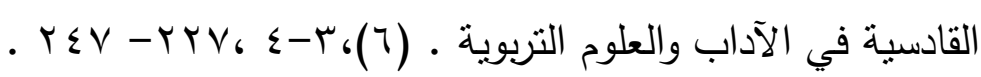

فتحي جراون (999 1) • تعليم التفكير :مفاهيم وتطبيقات. العين. الأمارات العربية المتحدة. دار الكتاب الجامعي.

ماجد الجلاد (T · . ץ).فعالية استخدام برنامج كورت في تتمية مهارات التقكير الابداعي

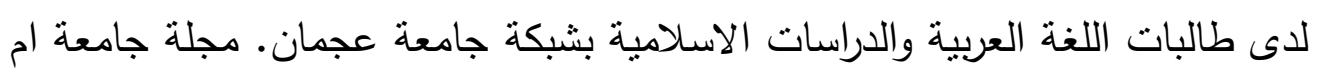

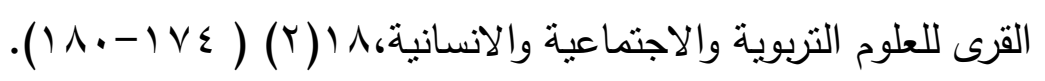
محمد جمل (^ . . r). تتمية مهارات التفكير الإبداعي من خلال المناهج الدراسية. العين، دار الكتاب الجامعي.

وزارة التربية والتعليم ،المعايير القومية لرياض الأطفال في مصر • (1 . ب) .مشروع

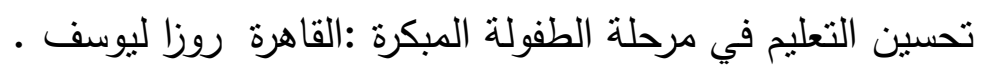

وليد صوافطة (^ . . ץ). تتمية مهارات التفكير الإبداعي واتجاهات الطلبة نحو العلوم

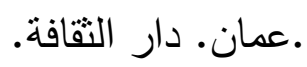

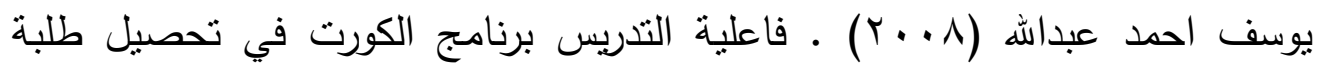

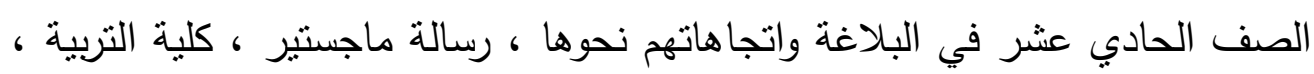

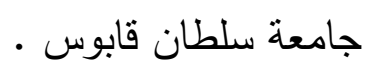

Barak , M \& Doppelt, Y .(1999) . Integrating cognitive research trust (CORT) Program for creative thinking into project -based 
برنامج الكورت لتعليم التفكير فى ضوء المعايير القومية لرياض الأطفال في مصر

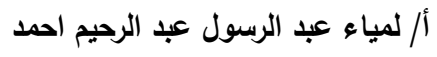

technology curriculum .Research in Science and Technological

Education , 17 (2) , 139 - 151 .

Kari S . Bauer \& Tina Schennum .(2007) . Mathematics Nevada's

Pre-Kindergarten Content Standards, State of Nevada Office of

Early Care \& Education Department of Education . Nevada .

Suleiman , Z. (2011) . effectiveness of a training program based

on cognitive research trust strategies to develop seventh grade

students critical thinking in history course, journal of social

sciences

, $3,436-442$.

van kessel, P.(2007).CORT transfer and behavior process of inquiry, London, university of roe Hampton . 